\title{
HACIA UNA NUEVA DOGMÁTICA JURÍDICA ENTRE ANÁLISIS ECONÓMICO Y LA FILOSOFÍA MORAL
}

CRISTIAN RICARDO A. PIRIS

UNIVERSIDAD NACIONAL DEL NORDESTE 


\title{
RESUMEN
}

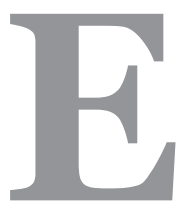

n el siglo XIX el pensamiento jurídico occidental llegó a su cenit con la aprobación de los códigos decimonónicos, perdiendo sofisticación en sus desarrollos posteriores. A partir de ese momento la tarea del jurista giró en torno a los comentarios o críticas de los códigos, siendo sus propuestas fácilmente clasificable como de lege lata o de lege ferenda.

Ese modo de ver la realidad o pretender involucrarse en ella, a partir de los textos legales, se fueron mostrando insuficientes, al punto que hoy se requiere una nueva dogmática más comprometida con valores, argumentos y análisis consecuencialistas que con inferencias puramente normativas.

Desde el common law nos llega una propuesta metodológica basada en el análisis económico de las instituciones legales y la filosofía moral como estructuras de pensamiento que compiten entre sí, a efectos de brindar las mejores soluciones jurídicas.

Si bien el common law es más permeable a esos razonamientos dado que el proceso de codificación nunca los alcanzó, en el Derecho Continental fenómenos tales como la constitucionalización, internacionalización y los acelerados avances producidos en el contexto de la sociedad del conocimiento vienen a romper los moldes del pensamiento iusprivatista, obligando a los juristas a introducir nuevas herramientas conceptuales y metodológicas para pensar el Derecho.

Palabras claves: Argumentación Jurídica - Dogmática Civil - Filosofía Moral - Análisis Económico del Derecho.

\begin{abstract}
Western legal thought reached its zenith with the approval of the nineteenth century codes, losing sophistication in their previous post-development. From that moment the lawyer's task focused on the comments or criticisms of codes, their proposals being easily classifiable as de lege lata or de lege ferenda.

This way of seeing reality or pretend to engage in it, from the legal texts, were to be insufficient to the point that it now requires a new dogmatic more committed to values, consequentialist arguments and analysis that purely normative inferences.

From the common law comes a methodological proposal based on the economic analysis of legal system and moral philosophy and structures of thought competing for the purposes of providing the best legal solutions.

While the common law is more permeable to these arguments as the coding process never reached in Continental law constitutionalization phenomena such as, globalization and the rapid advances in the context of the knowledge society are to break iusprivatista molds of thought, forcing lawyers to introduce new conceptual and methodological tools for thinking about the law.
\end{abstract}

KEYWORDS: Legal Argumentation - Civil Dogmatic - Moral Philosophy - Law and Economics. 


\section{EL PROBLEMA}

Spector (2003, p. 241) afirma que "en la Edad Media, la doctrina jurídica iusprivatista comenzó a desarrollar una estructura teórica capaz de explicar y sistematizar el conjunto de normas de Derecho Romano. Este proceso culminó durante los siglos XVIII y XIX con la redacción de los códigos civiles europeos y latinoamericanos. Luego de que la codificación fue puesta en práctica, y completada con la sanción del Código Civil alemán (BGB), la ciencia jurídica comenzó a declinar en vitalidad intelectual. Aunque los juristas todavía trabajan en la sistematización de las normas codificadas y, en particular, de las decisiones judiciales que buscan ajustar el código a las nuevas circunstancias económicas, sociales y tecnológicas, esta actividad carece de la sofisticación teórica que marcó los estudios civilistas de la pre-codificación, en gran medida, esto se debe al hecho de que los juristas completaron, a todos los efectos prácticos el proceso de redescubrimiento y sistematización del Derecho Romano que sentó las bases para la codificación”.

Luego continúa diciendo que "en las últimas décadas, los juristas norteamericanos han producido una revolución intelectual al aplicar la economía y la filosofía moral al estudio de instituciones jurídicas particulares. Los analistas económicos del derecho y los filósofos del derecho compiten en tratar de ofrecer la explicación más exitosa de diferentes campos del common law" (Spector. 2003, p. 241-2).

Antes de entrar de lleno el tema de los aportes del análisis económico y de la filosofía moral, vale mencionar algunas cuestiones para contextualizar las afirmaciones de Spector.

En primer lugar, es bien sabido que una vez culminada la codificación francesa el deslumbramiento ante tamaña obra intelectual se vio reflejado en la escuela de la exégesis. Pero no se trató de un caso aislado, de un fenómeno puramente francés. "La configuración de la ciencia jurídica como un saber que tiene como objeto el Derecho positivo supone situarse en el momento histórico concreto que se caracteriza por la desaparición del Derecho natural de la cultura jurídica. En efecto, a comienzos del siglo XIX surgen en Europa tres escuelas (la escuela histórica en Alemania, la escuela de la exégesis en Francia y la escuela analítica en Inglaterra) que tienen en común la idea de que la ciencia jurídica debe dedicarse a estudiar el Derecho positivo, que se concibe como un Derecho «puesto» (ius positum) ya sea por el pueblo en su propio «desenvolvimiento orgánico», por el autor de un código o por el soberano". (Sastre Ariza. 2001, p. 581).

Las distintas escuelas del positivismo ven al Derecho positivo como algo externo a la ciencia jurídica, un objeto que es tomado por ésta y sobre la cual desenvuelve su labor científica.

La decisión metodológica de circunscribir la ciencia jurídica a textos normativos supone la "aceptación dogmática de la fuerza obligatoria del derecho positivo" (Nino. 1998, p. 322) y tiene muchas consecuencias, entre ellas independiza el estudio del derecho de consideraciones referidas a la moral, la política o el comportamiento de los destinatarios de las normas. Quizás el modelo positivista más extremo lo sostuvo Kelsen con su “Teoría Pura”, quien sostenía que la ciencia jurídica para ser tal debía estar exenta de todo elemento extranormativo, valorativo o ideológico.

Ceñir el estudio del derecho al Derecho positivo no estuvo exento de críticas e intentos de superación como la escuela de la libre investigación científica de Geny y Bonnecasse, del derecho 
libre, la jurisprudencia de intereses, etc. Si bien muchos de estos intentos fueron certeros a la hora de señalar críticas al positivismo, en cambio no fueron igualmente eficaces en miras a diseñar un modelo alternativo de ciencia jurídica para proceder a su reemplazo. De allí, entonces, la importancia de los desarrollos teóricos que se produjeron en el common law estadounidense en las últimas décadas, aplicando la economía y la filosofía moral al estudio de instituciones jurídicas.

En el presente trabajo haremos una breve reseña de las propiedades caracterizantes del análisis económico y de la filosofía moral que en otras latitudes se aplica al estudio del Derecho Privado.

En otro orden cosas, hasta hace poco tiempo atrás era posible referirse al Derecho Privado solo aludiendo a la ley, la jurisprudencia o la doctrina, y haciendo total abstracción de la Constitución o los Tratados internacionales. Hoy esto es impensable. Ha sido de tal magnitud la irrupción de las nuevas fuentes que debemos repensar todo el sistema a partir de las nuevas jerarquías y relaciones que vienen a establecerse.

La constitucionalización y transnacionalización del Derecho Privado son dos nuevos paradigmas, a partir de los cuales resulta necesario reconstruir nuestras instituciones jurídicas.

Básicamente, es necesario comprender que debemos salir de la seguridad y tranquilidad decimonónica para adentrarnos en un terreno incierto, que necesita todavía de una Teoría General remozada que dé cuenta de las nuevas fuentes -actuales y por venir-, y de las relaciones y jerarquías que se establecen entre ellas. Utilizando la jerga posmoderna, el sistema de fuentes ha salido del estado sólido -concreto, preciso, delimitado para tornarse al estado líquido -fluido, blando, indeterminado-.

En todo caso, la constitucionalización del Derecho Privado exige una reflexión profunda que debe comprender distintas dimensiones de abordaje que excede lo normativo, y va desde lo descriptivo hasta lo analítico de la dogmática privatista y, al mismo tiempo, del Derecho Constitucional. Pero también exige al jurista privatista indagar en campos poco frecuentados como la voluntad del constituyente, los valores fundacionales, los principios fundamentales, el contexto socio-histórico existente al momento de la creación de la norma, etc.

Por otra parte estamos viviendo acelerados cambios sociales, al punto que las fluidas variaciones en el campo de las tecnologías, la industria, las estructuras sociales, las relaciones humanas, etc., cada vez se hacen más difíciles de fijar en los rígidos moldes jurídicos porque como se señala con frecuencia, no estamos frente a una época de cambios sino a un cambio de épocas.

Por todo ello es necesario articular una nueva labor jurídica privatista que no se halle excesivamente apegada a los textos normativos, generando una dogmática indiferente a la realidad social y los fundamentos que le dan origen a las instituciones jurídicas.

A partir del renacimiento, pero especialmente en los siglos XVII y XVIII, los juristas se constituyeron en "ingenieros" institucionales; es decir, nada menos que quienes diseñaron las instituciones modernas, pero eso funcionó así hasta el siglo XIX porque como dice Alfaro "la magna opera de racionalización que supusieron los códigos no fue una comida gratis. Convirtió a los juristas en exégetas. Dejaron de ser productores de Derecho e ingenieros sociales para con- 
vertirse en funcionarios" (Alfaro Águila-Real, 2007).

El objetivo del presente trabajo no consiste en hacer una crítica al positivismo, ni brindar una mirada panorámica del "estado del arte" sobre el capítulo de la interpretación jurídica, o discurrir sobre las virtudes de los distintos modelos posibles de ciencia jurídica. Partimos de la base que los juristas reales por estas latitudes, más allá de cómo se definan, básicamente realizan sus labores cotidianas describiendo y sistematizando Derecho positivo, pero los resultados son cada vez más insatisfactorios porque hay mucho campo "jurídico" que queda sin ser relevado y hay demasiadas situaciones socialmente relevantes que no pueden ser aprehendidas. En este trabajo intentaremos describir las propiedades caracterizantes del Análisis Económico del Derecho y de la Filosofía Moral aplicable al mundo jurídico, en la búsqueda de entender el "nuevo Derecho" que se está gestando en los EEUU.

\section{EL ANÁLISIS ECONÓMICO'}

El Derecho es un subsistema integrante del sistema social como lo son también la política, la moral y la economía. Desconocer que los distintos subsistemas se interpenetran; es decir, se influyen y son influidos por los otros es desconocer cómo operan las instituciones en una sociedad.

Cualquier persona, sin deformaciones profesionales, intuitivamente podría dar cuenta de esto sin mayores inconvenientes.

En primer lugar el Análisis Económico del Derecho (AED) es una manifestación particular de las complejas vinculaciones que existen entre el Derecho y la Economía.

En este sentido podemos encontrar reflexiones económicas en torno a la ley en las obras de los precursores de la Ciencia Económica, como Adam Smith, Jeremy Bentham y Karl Marx. En Argentina, Juan Bautista Alberdi fue un ilustre precursor de los estudios jurídicos vinculados con los económicos (Diaz, 2006).

Owen Fiss (2001, p. 52-3) explica que “... cualquier mercado que funciona bien necesita del derecho"; en ese sentido, "por lo menos, el mercado requiere dos sistemas de derecho. El derecho inmobiliario es esencial para determinar quién es dueño de qué, una precondición para el comercio. También garantiza a los dueños de propiedad que ellos cosecharán el beneficio de cualquier inversión que vayan a hacer y así, provee incentivos para invertir. El derecho de contratos es también indispensable para garantizar a todos los interesados que estén negociando entre sí, que sus promesas serán respetadas.

\footnotetext{
${ }^{1}$ Como dato ilustrativo que puede indicar la relevancia del tema, vale mencionar que por Acordada 36/2009, la Corte Suprema de Justicia de la Nación resolvió crear la “Unidad de Análisis Económico" (http://www.cij.gov.ar/nota-2271-La-Corte-creo-una-unidadpara-analizar-el-impacto-economico-de-sus-sentencias.html). Se expresa en los fundamentos, que las atribuciones jurisdiccionales la Corte, en ejercicio de que le otorga la Constitución, tienen efectos económicos y mencionan una veintena de normas constitucionales que hacen directa alusión a cuestiones económicas, de las cuales la Corte debe precisar los alcances jurídicos. Se trata, nada menos, de un cambio de visión, un primer paso para morigerar una dogmática de reglas a otra más atenta a las consecuencias.

Por este tema puede consultarse los siguientes artículos: SOLA, Juan Vicente (2009). "La Corte Suprema y el análisis económico del derecho", LA LEY 2009-E, 1223. SAGÜÉS, María Sofía (2009). “El análisis económico del derecho en la jurisdicción constitucional: ponderación de la Unidad de Análisis Económico de Derecho de la Corte Suprema de Justicia de la Nación Argentina”, en LA LEY 2009-F, 1114.
} 
Estos dos sistemas de derecho -y otros, tales como el derecho de responsabilidad civil y de antimonopolios, que pueden ser necesitados para que el mercado funcione- obviamente no se hacen valer por sí mismos. El mercado también necesita una institución que pueda interpretar e implementar pertinentes rules of law: un poder judicial. Esta institución debe ser independiente de los contendientes interesados así como de las mayores fuerzas sociales y políticas".

Pero aun así, para los juristas las relaciones entre Derecho y Economía, no son de interdisciplina; usualmente, el Derecho tomó al dato económico como el supuesto de hecho de la norma jurídica. En este sentido "lo característico es un papel ciertamente pasivo de la Economía en este tipo de análisis, ya que se limita a integrar el concepto de 'supuesto de hecho' o fattispecie. (...) Desde este punto de vista, el Derecho permanece neutral frente a las asignaciones que opera el mercado, antes y después de que la norma iusprivatista lo regule. (...) El cambio actual es, justamente, la pérdida de neutralidad del Derecho Privado frente a la Economía” (Lorenzetti. 1999, p. 66-7).

Santos Pastor nos indica que hay muchas maneras de enfocar el estudio del Derecho pero la más usual es el análisis jurídico-formal, es decir, una labor interpretativa sobre el sistema jurídico. En este caso "el análisis de la norma la define y fija su alcance y significado con arreglo al tenor literal, espíritu, concordancias, analogías, voluntad del legislador, posición en la estructura y jerarquía de fuentes, relación con los precedentes judiciales o legislativos, encaje en los principios generales del Derecho, contexto social, análisis de la estructura de la propia norma, etc.” (Pastor. 1989, p. 28).

En la actualidad resultan evidentes los límites de la dogmática tradicional para explicar y comprender el complejo fenómeno jurídico. Una muestra de ello es la imposibilidad de servir de guía para el legislador, el dogmático se ocupa solo de un objeto dado, el Derecho Positivo. Así, sus esfuerzos se vuelcan a un estudio interno del sistemático jurídico, "por ello resulta plenamente justificada la crítica que apunta a los juristas [dogmáticos] como seres poco sensibles al análisis de los problemas jurídicos desde el punto de vista de su justicia o injusticia, de sus consecuencias sociales o de sus costes y su eficiencia” (González Amuchástegui. 1994, p. 931).

Como expresa Sola (2008, p. 1350), los abogados "utilizamos argumentos normativos, sobre las fuentes históricas del texto analizado, sobre los precedentes judiciales a que dio origen y finalmente conceptos mucho más indeterminados como los fundamentos éticos de la norma. Raramente analizamos las consecuencias de una norma jurídica o de una decisión judicial. El Derecho y la Economía nos proponen concentrarnos en los efectos económicos de las normas, ya sea que éstas provengan del texto en sí mismo o a través de su concretización en precedentes. La herramienta utilizada del análisis económico del derecho es un análisis de los incentivos, evidentes u ocultos, que crean las normas jurídicas para determinar sus consecuencias, algunas de ellas inesperadas. Asocia la ciencia normativa más antigua, como es el derecho, con la ciencia social más precisa en sus predicciones, como es la economía, y esta unión revoluciona la visión del derecho".

Retomando a Santos Pastor, éste señala que el análisis jurídico-formal “es un conocimiento 
autónomo que no requiere otro campo de aprendizaje” (Pastor. 1989, p. 28). Pero que “... si nos preguntamos por la justificación o explicación de la existencia de una norma o institución jurídica, existente o propuesta, y por su efectos o consecuencias, de poca, si alguna, utilidad nos será el análisis jurídico formal. (...) y en ese sentido entiendo que el Derecho puede ser examinado mejor con los métodos y técnicas de las ciencias sociales." (Pastor. 1989, p. 29).

Básicamente de eso se trata el AED, de examinar el Derecho con otros métodos y técnicas que no corresponden al análisis jurídico-formal.

Indudablemente, cabe la pregunta de por qué sometemos al derecho a un análisis económico, y no sociológico, antropológico, o psicológico, por citar algunas disciplinas.

Algunos autores afirman que esto es así por cuanto la ciencia económica es la ciencia social mas avanzada; en este sentido Lorenzetti (1999, p. 62) asevera que sometemos al Derecho a un análisis económico porque es la ciencia económica "la que más rigurosamente había estudiado la conducta humana y extraído reglas que la hacían predecible...”.

Además, la economía cobra una importancia especial para nosotros porque no sólo nos aporta un conjunto de herramientas útiles y sofisticadas, sino se ocupa de un objeto que no puede resultarnos extraño. Según la muy difundida definición de Robbins, retomada por Cooter y Ulen (1998, p. 22), la Economía es la "ciencia que estudia la conducta humana como una relación entre fines y medios escasos susceptibles de usos alternativos”; es decir es una ciencia que se ocupa de las elecciones racionales de los seres humanos.

Otro prestigioso economista, Hal Varian (1998, p. 601), afirma que "en los últimos años, el análisis económico se ha convertido en algo habitual en la teoría y práctica del derecho. Porque es fácil ver la afinidad natural que existe entre estas dos disciplinas: ambas comparten el objetivo de comprender las instituciones sociales. Ambas tienen, además, un importante componente normativo: tanto el derecho como la economía se ocupan no sólo de indagar cómo funcionan las instituciones sociales, sino también de cómo mejorar su funcionamiento".

Ahora bien, el nuevo AED no subsume a cualquier intento de reivindicar el análisis económico del fenómeno jurídico; básicamente se caracteriza, en primer lugar, por establecer estrechas relaciones entre la microeconomía y el derecho privado, pero esto no es exhaustivo, por cuanto existen importantes manifestaciones del análisis económico referido a otros campos del derecho como el referido a los delitos penales o la libre competencia.

Se caracteriza, en segundo lugar, por aplicar la teoría económica y los métodos empíricos de la ciencia económica al estudio de situaciones jurídicas. Pero lo llamativo es que esas situaciones jurídicas pertenecen a áreas del Derecho tradicionalmente ajenas a la reflexión económica. No es extraño para nosotros, al menos "alguna" reflexión económica en materia de defensa de la competencia, seguros, tributos, servicios públicos, etc. A esto algunos autores, como Posner, han denominado el viejo AED. El nuevo AED o simplemente AED introdujo la novedad de traspolar el análisis económico al estudio de normas que regulan comportamientos que se dan fuera del mercado.

Podemos afirmar que "el supuesto fundamental de este análisis es que las normas jurídicas crean costos y beneficios para la realización de determinadas acciones, con lo cual el Dere- 
cho deviene susceptible de un tratamiento a la luz de la teoría de precios, a su vez una rama de la microeconomía” (Spector. 2004, p. 8).

Como afirma Mercado Pacheco (1994, p. 27), lo común y definitorio del AED es la aplicación de la teoría económica en la explicación del Derecho. Pero con más precisión podemos afirmar que lo definitorio del AED es la aplicación de la teoría económica, principalmente la teoría de precios, para analizar la formación, estructura, proceso e impacto que tienen la ley y las instituciones legales.

El AED propone un doble objetivo para el Derecho: "proveer las condiciones necesarias para que el mercado funcione e imitar al mercado cuando su libre desenvolvimiento no sea factible" (González Amuchástegui.1994, p. 935).

Según Calabresi, se puede hablar de Derecho en términos de justicia y derechos (que es lo que hacemos mas frecuentemente), o en términos de costos y beneficios (es lo que propone Posner), o combinando ambos lenguajes.

Podemos afirmar que el AED, o nuevo AED, nace en la década del '6o en los Estados Unidos, a partir de los trabajos de Ronald Coase, Guido Calabresi, Gary Becker y Richard Posner.

Allá por la década del '50 en los EEUU, profesores de las Facultades de Derecho y Economía de la Universidad de Chicago, descubrieron el gran poder explicatorio que tenía el análisis microeconómico sobre diversos aspectos de la vida humana. Desde un punto de vista metodológico se trataba de aplicar a un amplio abanico de las actividades humanas el supuesto de comportamiento racional maximizador, de ese modo era posible establecer proposiciones con validez empírica sobre la forma como reaccionarían los individuos frente a determinados cambios en su entorno, elaborando a partir de estos antecedentes propuestas de reforma legal, basadas en el criterio de eficiencia económica.

El AED es actualmente una corriente de pensamiento gestada y desarrollada principalmente en Escuelas de Derecho de Yale y Chicago, por Calabresi y Posner respectivamente. Ha obtenido un gran predicamento en ese país y de a poco empieza a ser utilizado en otros lugares como por ejemplo Canadá, Alemania, Italia y España, aunque algunos autores afirman que el AED viene a solucionar un problema "local" del realismo jurídico anglosajón, y lo ven "como una salida tecnocrática a la crisis de la teoría jurídica americana de los últimos cincuenta años" (Mercado Pacheco. 1994, p. 274).

\section{LAS PROPIEDADES CARACTERIZANTES DEL AED}

Bajo el rótulo de AED se engloban diferentes formas de aproximarse al fenómeno jurídico, unas básicamente de carácter descriptivo y otras de carácter normativo.

El AED puesto en función descriptiva utiliza el principio de eficiencia como herramienta a la hora de explicar normas jurídicas y fallos judiciales. En estos casos se toma al Derecho como algo dado y se lo somete a la descripción y explicación eficientista. En este sentido, el Derecho es en términos generales eficiente, y lo será en el futuro, por lo que resulta posible predecirlo. 
Las diferentes críticas formuladas al AED descriptivo y que no resulta pertinente desarrollar aquí, brindaron mayores argumentos a su rama normativa, según la cual es posible utilizar el AED como guía para jueces y legisladores, y avanzar propositivamente proyectando nuevas normas jurídicas y fallos judiciales en función de la eficiencia económica.

Para esta última rama los conceptos normativos utilizados hasta ahora son definidos "como un irremediable embrollo de intuiciones y por ello ofrece una estructura analítica para ordenar dichas intuiciones y darles contenido. Esta estructura es el mercado. De acuerdo a esta rama del análisis económico del derecho, los conceptos normativos del Derecho deben ser construidos y aplicados de manera tal de hacer al poder Judicial un instrumento para perfeccionar el mercado".

Además de esto existen otras variantes metodológicas del AED, por ejemplo la versión predictiva, según la cual tomando en consideración que las personas son agentes racionales que buscan maximizar sus beneficios, será posible predecir como se comportaran a partir de los incentivos y desincentivos que generan las normas jurídicas. También se encuentra la tesis evolucionista por la cual se afirma que el Derecho tiende a adoptar normas eficientes (Spector. 2004, p. 13).

En cualquiera de las vertientes del AED, se verifican los siguientes presupuestos:

\section{1.a) Eficiencia}

La principal preocupación, que constituye una materia central de la ciencia económica, es “... saber cómo debe utilizar una sociedad los recursos limitados de que dispone, para conseguir el mayor grado de satisfacción de las necesidades” (Schäfer y Ott. 1991, p. 21). Esta es una preocupación que recorre transversalmente todas las reflexiones rotuladas como "económicas".

Básicamente existen dos tipos de eficiencia, la referida a la producción y a la asignación. La eficiencia productiva alude al logro de un estado de cosas en el cual sea posible producir más de algún bien sin producir menos de ningún otro bien.

La eficiencia en la asignación es un concepto un poco más complejo y fue originalmente definido por el economista y sociólogo italiano Wilfredo Pareto. Para este autor una situación distributiva es superior a otra cuando la utilidad o beneficio de un agente económico aumenta sin que por ello disminuya la utilidad o beneficio de ningún otro agente; es decir, cuando al menos un agente económico se encuentre mejor sin que nadie se encuentre peor, a esto se denomina Superioridad de Pareto. En esta línea de razonamiento una situación es óptima cuando ya no es posible aumentar la utilidad de un miembro de la sociedad sin empeorar la situación de otro sujeto, a esto se denomina Óptimo de Pareto. Por definición el escenario montado por Pareto conduce a situaciones donde no existen perdedores, por ello no es necesario realizar comparaciones interpersonales. Va de suyo que la optimalidad de Pareto solo es posible en el espacio de los intercambios voluntarios; vale decir, en el ámbito contractual paritario sin asimetrías.

Obsérvese que este criterio es indiferente a consideraciones de justicia distributiva, dado que un estado social determinado puede ser perfectamente óptimo con algunas personas en la más absoluta indigencia y otras en la opulencia, tanto es así que no sería posible mejorar la si- 
tuación de los pobres a costa de reducir en algo los lujos de los más ricos porque estos pasarían a estar peor que antes.

La gran limitación del criterio paretiano es que no admite "perdedores", y la gran mayoría de las normas jurídicas generan beneficiados y perjudicados, por ello tiene sentido realizar comparaciones interpersonales a efectos de determinar si existen más beneficiados que perjudicados, y la cuantía de ese beneficio.

Por resolver problemas como estos los economistas Nicholas Kaldor y John Hicks, sostuvieron un principio paretiano morigerado, que lleva su nombre, eficiencia Kaldor-Hicks. Según este criterio es posible respetar a Pareto aun cuando existiese un miembro de la sociedad perjudicado. En este sentido una determinada situación social es preferible a otra si al menos un miembro de la sociedad resultara beneficiado, $\mathrm{y}$ al menos un miembro resultara perjudicado, si y solo si, resultase posible indemnizar a éste con parte del beneficio de aquel, y aun así siguiera teniendo una ventaja neta.

A los efectos prácticos, es difícil medir las utilidades de los sujetos, por ello se recurre a la moneda como escala de referencia de ésta. Según la difundida definición de Von Thur la moneda es aquella cosa mueble que el comercio utiliza como medida de valor para toda clase de bienes, pudiendo por lo tanto emplearse como medio general de cambio. Así, el beneficio o utilidad se traduce en un parámetro más objetivo, la moneda, que en términos generales es denominado riqueza. Esto lleva a algunos analistas económicos del Derecho, como Posner, a sostener abiertamente que eficiencia en el ámbito del AED debe entenderse como maximización de la riqueza de la sociedad.

Según Dworkin existe una diferencia sustancial entre el AED de los economistas y el de los juristas. Según el AED de los primeros el objetivo a lograr es la eficiencia, pero según el AED de los segundos es maximizar la riqueza, que según este autor - quizás el más importante filosofo del Derecho del siglo XX- no es lo mismo en muchos sentidos; pero no corresponde explayarnos en esta cuestión en este momento.

Como hemos visto, en términos generales, la eficiencia alude a la relación entre los beneficios totales de una acción o situación determinada puesta en contraste con los costos totales de la misma. En este sentido se puede afirmar que estamos frente a un estado de cosas eficiente cuando se aumentan los beneficios totales y se disminuye los costos totales.

En este sentido el AED considera “... como tarea legítima y necesaria de la ciencia jurídica, analizar en qué medida las reglamentaciones jurídicas evitan el despilfarro de recursos y aumentan la eficiencia” (Schäfer y Ott. 1991, p. 21).

El concepto de eficiencia, como el de justicia, son relativamente simples. El problema radica en la selección de los criterios que nos conducen a esos puntos de llegada, pero principalmente qué estamos dispuestos a sacrificar para obtenerlos.

Debe quedar muy claro que lo eficiente no es necesariamente justo, pero la inversa no vale en la mayoría de los casos. Aunque autores como Posner dirían que este planteo es equivocado visto que iguala los conceptos de justicia y eficiencia, reduciendo muchas veces el primero al segundo. 


\section{1.b) Consecuencialismo}

"La deontología y el consecuencialismo son dos tipos característicos de teoría ética. En el primer caso, el acento recae en los principios de acción, en las obligaciones que pesan sobre el agente moral (por ejemplo, decir la verdad), mientras que en el segundo lo importante es que algún objetivo valioso se cumpla en el mundo (por ejemplo, que la gente viva más feliz). Estas dos clases de 'estructuras éticas', como Mackie (1977) las calificaba, conllevan concepciones diferentes de lo correcto y del valor moral” (CEJUDO CÓRDOBA. 2010, p. 4).

De lo anterior se deriva que el AED es una teoría consecuencialista, visto que halla su "sustrato" justificatorio, es decir su fundamentación, no en algún precepto normativo (p. ej: la Constitución) o extranormativo (p. ej: Principios Generales del Derecho), sino ponderando las consecuencias de la norma; puntualmente si logra el objetivo de evitar el despilfarro de recursos.

Como expresan Rojas y otros (2012, p. 4) "las leyes, sentencias y demás reglas legales que componen el sistema jurídico contienen incentivos, y la hipótesis de que el hombre actúa con la finalidad de maximizar su bienestar permite una predicción de las respuestas de las personas a los cambios en las leyes, así como una explicación y evaluación de la eficiencia del sistema legal. De ese modo, tanto la situación del potencial criminal que debe decidir si comete un delito, de un empresario frente a la alternativa de gastar más, pero con precaución para evitar su responsabilidad por daños, o de quien afronta el dilema de cumplir o no un contrato, pueden ser examinados apelando al enfoque económico de la acción humana”.

\section{1.c) Escasez de bienes, individualismo, racionalidad, y universalización de preferencias}

Según Schäfer y Ott "las dos hipótesis legales más importantes de la teoría económica y de más aplicación práctica en la predicción científico-económica son la aceptación de la escasez de bienes y del individualismo metodológico" (Schäfer y Ott. 1991, p. 60).

La hipótesis legal de la escasez supone que en todos los campos de aplicación el hombre tiene necesidades ilimitadas y a la vez posee medios limitados para satisfacerlos. Por otra parte, la hipótesis legal del comportamiento racional egoísta (individualismo metodológico) acepta que por regla general los hombres intentan incrementar su propia utilidad y procurar su beneficio personal y saben muy bien lo que para ellos es útil o inútil.

El AED presenta un doble individualismo normativo y metodológico.

Según el individualismo normativo, el Estado solo puede trazar objetivos y delinear acciones (evidentemente aquí se incluye también la creación de normas jurídicas) "recurriendo a los objetivos y preferencias de los miembros de la sociedad" (Schäfer y Ott. 1991, p. 60), porque nadie se encuentra en mejores condiciones que los propios individuos de establecer qué es lo que más les conviene.

Según el individualismo metodológico los individuos son auto-interesados y tratan de maximizar su bienestar dentro de ciertas restricciones, aunque según Schäfer y Ott (1991, p. 60) lo hacen “... sin dejarse llevar por categorías morales o por la conciencia del deber”. Esto 
no significa que los individuos realicen efectivamente un cálculo de este tipo en todos los casos sino que se comportan "como si" lo hicieron. En esto se basa la denominada "soberanía del consumidor", una formulación central para entender el AED.

Tomando en cuenta lo anterior podemos decir que, como la premisa es que los bienes son escasos y no hay posibilidad fáctica de satisfacer todas las preferencias, cada individuo debe escoger alternativas y una decisión coherente será aquella que permita maximizar su bienestar y no reducirlo. En esto consiste la racionalidad. Cualquier conducta que no se adecue a este patrón no puede ser considerada racional; estos parámetros permiten extender los análisis mas allá del estricto ámbito subjetivo universalizando las preferencias de las personas.

También el AED cuenta con métodos propios en el estudio de los fenómenos y problemas jurídicos, donde el principal es la utilización de modelos analíticos.

\section{1. d) Modelos analíticos}

"La economía se basa en la construcción de modelos de los fenómenos sociales. Entendemos por modelo una representación simplificada de la realidad. (...) El poder de un modelo se deriva de la supresión de los detalles irrelevantes, que permite al economista fijarse en los rasgos esenciales de la realidad económica que intenta comprender" (Varian. 1998, p. 1).

Particularmente "el análisis económico utiliza un modelo: el mercado como método de asignación de recursos" (Lorenzetti, 1999, p. 72).

Como la realidad es compleja e intrincada, un modelo es una construcción artificial que nos permite recortar aquellos datos fácticos que nos parecen más significativos y operar sobre ellos, principalmente a los efectos de obtener predicciones y "descubrir principios generales que se apliquen en situaciones realistas mas complejas” (Fischer, Dornbush y Schmelensee. 1992, p. 2).

Muchas veces nos parecen absurdas las derivaciones que se obtienen de un modelo donde interactúan un consumidor y un proveedor, porque sabemos que en el mercado hay mucho mas que un proveedor y un consumidor; pero si no alcanzamos a comprender como actúan en un modelo ficticio dos actores, difícilmente podremos comprender como actúan una gran diversidad de actores en un mercado real.

Todo lo expuesto ilustra sobre cuál debe ser la función del Derecho para el AED. Si el mercado es la mejor herramienta con que cuenta la sociedad a los efectos de maximizar el bienestar (o la riqueza), entonces el rol del Derecho debe ser asegurar el funcionamiento del mercado, e imitarlo cuando éste no pueda actuar efectivamente.

Como los bienes finalmente se asignan a quienes mas lo valoran, entonces debemos buscar la optimalidad en la asignación de los mismos. Esto se logra, según Pareto, cuando se realizan intercambios voluntarios de modo tal que al menos alguien esté mejor sin que nadie se encuentre en peor situación. De allí la fuerza y protagonismo que se le asigna al principio de autonomía de la voluntad. 


\section{1. e) El teorema de Coase}

Una de las nociones básicas utilizadas por el AED es el llamado "Teorema de Coase", denominado así en honor al prestigioso economista que lo formuló en 1960, en un trabajo titulado "El problema del costo social".

Este teorema, en una enunciación simplificada, afirma que siempre se adoptará la solución más eficiente, cualquiera sea la asignación de la titularidad del derecho, siempre que los costos de transacción fueran igual a cero, vale decir inexistentes.

Pollinsky (1985) ejemplifica esto de la siguiente manera, imaginemos que una fábrica emite contaminantes al aire que causan daños a cinco vecinos al momento de colgar sus ropas por $\$ 75$, es decir un total de $\$ 375$. Estos daños que pueden eliminarse con la instalación de un filtro en la fábrica por un costo de $\$ 150$, o entregando a cada vecino una secadora por $\$ 50$ cada una, es decir con un costo total de $\$ 250$. Independientemente de que la fábrica tenga derecho a contaminar o los vecinos al aire puro, cualquiera de ellos optará por abonar los $\$ 150$ correspondientes al filtro; la diferencia consistirá en la redistribución de la renta, es decir quién hará frente al pago del filtro, ya que si se asigna el derecho a contaminar a la fábrica los vecinos pagarán el filtro; en caso contrario, la fábrica se hará cargo de los costos.

Pero si existieran costos de transacción positivos, por ejemplo si a cada vecino le cuesta $\$ 60$ reunirse con los demás, elegirían comprar la secadora por \$50 cada una. A las claras importa la adopción de una solución ineficiente, con lo cual la norma debería asignarle la titularidad del derecho a ellos por cuanto la fábrica, al no tener costos de transacción, escogería seguir pagando los \$150 del filtro. De esta forma es posible formular el teorema de Coase en una versión más compleja: si hubiese costos de transacción positivos, la solución eficiente no podría producirse con independencia de la norma jurídica escogida (Pollinsky. 1985, p. 25).

\section{LA FILOSOFÍA MORAL}

En este título se halla la pretensión de justificar éticamente las soluciones jurídicas, y para ello vamos a dar cuenta de aquellas construcciones en el ámbito de la filosofía moral que puedan servirnos de marco para acometer esa tarea.

Hasta mediados de los años '5o del siglo pasado el mundo anglosajón estaba dominado por el utilitarismo. Como se trata de una teoría con poca incidencia en el mundo continental corresponde hacer una breve reseña de su contenido.

Will Kymlicka (1995) reconoce dos versiones del utilitarismo, las cuales serían coincidentes en sus postulados pero diferirían en el ámbito de su desenvolvimiento. La primera versión se refiere al utilitarismo como una moral política, cuyo ámbito propio es "la estructura básica de la sociedad" y la segunda versión como una moral exhaustiva referida a la conducta particular de los individuos en todos los actos de la vida cotidiana.

Según este autor el utilitarismo se caracteriza por:

1. Una concepción particular de la "utilidad" (bienestar de la humanidad). 
2. Un mandato para desarrollar al máximo la "utilidad".

El utilitarismo no cuenta con una concepción unívoca de la utilidad, por el contrario cuenta con cuatro concepciones diferentes, a saber:

- Hedonismo del bienestar.

- Utilidad no hedonista de estados mentales.

- Satisfacción de preferencias.

- Preferencias informadas.

Según Kymlicka el utilitarismo es perfectamente compatible con cualquiera de estas concepciones, aunque pierde mucho de su atractivo cuando se separa al utilitarismo del hedonismo del bienestar. El utilitarismo no nos ofrece un criterio único y simple o un método científico para determinar qué es lo correcto y qué es lo incorrecto. En este sentido el utilitarismo no tiene ventajas, pero tampoco desventajas frente a otras teorías. Entonces, si por algo resulta cuestionable el utilitarismo es por la idea de desarrollar al máximo la utilidad y no por las concepciones mismas de utilidad.

\section{Desarrollar al máximo la utilidad}

El mandato utilitario consiste en desarrollar al máximo la utilidad (cualquiera sea la concepción que tengamos de ella). Todas las preferencias de los individuos tienen igual valor pero qué sucede si el fomento del bienestar de una persona entra en conflicto con el fomento del bienestar de otras personas.

En principio las preferencias de una persona deben quedar insatisfechas si entran en conflicto con lo que desarrolla al máximo la utilidad general; ya que las utilidades de las personas tienen igual valor no hay razón para dar prioridad a los intereses de las minorías.

Este compromiso con el examen de las consecuencias para el bienestar de la humanidad es uno de los atractivos del utilitarismo en comparación con las teorías que nos dicen que tenemos que seguir las tradiciones o las leyes divinas sin tomar en cuenta las consecuencias para la humanidad.

Pero cuando no podemos satisfacer todas las preferencias, nuestras intuiciones no nos dicen que idénticas cantidades de utilidad deberían tener el mismo peso.

Un claro ejemplo de esto nos brinda David Brink a través de un hipotético "Agente - U”, ejemplo de un utilitarista moral exhaustivo que ante cada decisión a tomar debe realizar un cuidadoso cálculo de utilidad (análisis de cuales acciones desarrollan al máximo la utilidad). Inexorablemente deberá enfrentarse a dos grandes problemas:

A. Relaciones especiales: intuitivamente todas las personas tenemos relaciones morales especiales con nuestros amigos, familiares, personas a las que nos unen contratos, gratitud, etc. pero para el "Agente - U” esto no tendría mayor relevancia, no abría razón para sentirse con una mayor obligación frente a ellos. Esta postura no es altruista o extremadamente generosa como pretende ser descripta, sino absurda, porque cualquier vida que valga la pena ser vivida es aquella compuesta por vínculos especiales que estructuran y dan dirección a la propia 
existencia. La esperanza de posteriores logros o progresos a partir de determinados compromisos es lo que da significado a nuestras presentes acciones.

B. Preferencias ilegítimas: El utilitarismo sostiene que cada persona debe tener igual importancia en nuestro proceso decisorio y por ello a cada fuente de utilidad se le debe conceder una importancia igual. Pero intuitivamente no todas las preferencias tienen igual peso, deberían quedar excluidas las preferencias "ilegítimas", es decir aquellas que implican negarle a alguien algo que le corresponde "por derecho", pero para el "Agente - U” no existe nada que corresponda a alguien "por derecho" previo al cálculo de utilidad.

Parece entonces que el "Agente-U”, al tratar de incrementar la utilidad se aleja de nuestra idea intuitiva respecto del consecuencialismo, que constituye uno de los elementos caracterizantes del utilitarismo.

A esta crítica algunos utilitaristas responden que determinados actos, como vulnerar relaciones especiales o derechos básicos resultarían desautorizados si cambiásemos a un procedimiento decisorio más elaborado. Deberíamos pasar de un utilitarismo "de actos” a un utilitarismo "de reglas". Entonces la clave del "Agente-U” está en determinar qué conjunto de reglas desarrollan al máximo la utilidad; en este sentido afirman que, en términos utilitaristas, estaríamos mejor manteniendo relaciones especiales y respetando derechos que siguiendo una regla que subordina estos principios a cálculos de utilidad.

El utilitarista de actos realiza una evaluación de utilidad de los actos individualmente considerados. El utilitarista de reglas realiza un test de utilidad sobre determinadas reglas, independientemente que un acto aislado incluido en la regla no satisfaga al principio de utilidad; la cooperación social requiere del seguimiento de reglas, por lo que deberíamos evaluar las consecuencias de convertir en regla una determinada forma de actuar.

Pero aun suponiendo que el utilitarismo de reglas pueda llegar a un nivel de desarrollo tan detallado y rígido que las convierta en un equivalente al utilitarismo de actos resulta demasiado optimista suponer que las reglas para incrementar la utilidad van a proteger siempre los derechos de los débiles y las minorías impopulares. Incluso suponiendo que así fuese se llegaría a esta conclusión loable por un camino incorrecto, se debe evitar causar un mal a una persona porque no merece sufrir injustamente y no por los posibles efectos sobre otras personas a largo plazo.

La objeción contra el procedimiento decisorio utilitarista es que ciertas obligaciones especiales deben ser incluídas y ciertas preferencias ilegítimas excluidas, y que estos requisitos morales tienen prioridad sobre el máximo desarrollo de la utilidad. Entonces, resulta irrelevante frente a esta crítica la postura de los utilitaristas de regla que sostienen que la obediencia a las promesas, no tener en cuenta prejuicios irrazonables, etc., hacen que la utilidad alcance su máximo valor a largo plazo; no porque reconocer relaciones especiales y excluir preferencias ilegítimas no sean buenos instrumentos para el máximo desarrollo de la utilidad sino porque de modo alguno constituyen instrumentos. Este problema no se evita aplicando el criterio de utilidad a las reglas y no a los actos, desde el punto de vista de la moral cotidiana el problema radica en aplicar dicho principio de utilidad. 
Algunos utilitaristas estarían de acuerdo con estas críticas y dirían que es correcto y apropiado que nuestros vínculos tengan prioridad sobre la búsqueda de la utilidad general. Sostienen que no deberíamos ser "Agentes-U” que deciden cómo actuar a partir de cálculos utilitaristas, y que ven las promesas como instrumentos para alcanzar la máxima utilidad. Por el contrario, deberíamos conceder a las promesas y a los derechos de las personas tal importancia que fueran invulnerables frente a los cálculos de intereses sociales.

En definitiva, no deberíamos ser utilitaristas en nuestros razonamientos morales, en nuestros procedimientos decisorios. Pero no porque el utilitarismo sea incorrecto sino todo lo contrario, porque por esta vía tenemos mayores posibilidades de desarrollar a máximo la utilidad. En definitiva, sostienen que una sociedad de no utilitaristas que crean en la importancia intrínseca de las promesas y los derechos actuará mejor (maximizando la utilidad) que una sociedad de utilitaristas de actos o de reglas que vean en las promesas y los derechos instrumentos para el máximo desarrollo de la utilidad. Aunque resulte paradójico el utilitarismo, según esta versión, es esencialmente un criterio de corrección y no un procedimiento decisorio. Entonces lo que define al utilitarismo es la afirmación que el acto correcto es el que desarrolla al máximo la utilidad, no la afirmación de que deberíamos deliberadamente tratar de desarrollar al máximo la utilidad. Entonces queda abierta la pregunta acerca de que procedimiento decisorio deberíamos usar. Es bastante posible que obremos mejor, de acuerdo con los criterios utilitaristas de corrección, empleando un procedimiento decisorio no utilitarista. En consecuencia deberíamos ser "utilitaristas indirectos".

De las dos versiones desarrolladas en apretado resumen interpretamos que el utilitarismo como moral exhaustiva no resulta plausible, por las numerosas críticas arriba consideradas. Principalmente, un utilitarista moral exhaustivo lejos de ser un componente útil de la sociedad se transforma en un ente totalmente desprovisto de relaciones humanas relevantes y hasta podría convertirse en un sujeto ciertamente peligroso desde el punto de vista que no reconocería derechos adquiridos o libertades básicas frente al cálculo de utilidad. Incluso la propia existencia de este utilitarista resultaría totalmente insatisfactoria; por un lado llevaría una vida vacía de contenidos, con amigos, familiares, etc. con quiénes no tendría ningún compromiso especial y por otro lado viviría lleno de temores ya que no podría evaluar en que circunstancias el cálculo de utilidad resultaría contrario a sus convicciones más profundas o exigiría privarle de determinados bienes sociales básicos.

Las distintas reformulaciones del utilitarismo (de actos a reglas y de procedimiento decisorio a criterio de corrección) tampoco resultan plausibles desde la posición del “Agente-U”, ya que hace uso de argumentos artificiosos para tratar de lograr una cierta adecuación a intuiciones muy profundas que el utilitarista moral exhaustivo no interpreta suficientemente.

Existen relaciones especiales que no se pueden desconocer, la vida del hombre es una vida plena de compromisos y es deseable que así sea siempre que esto no implique privar a otros de bienes sociales primarios y, por otro lado, existen ciertas preferencias e intereses que no pueden ser tomados en cuenta desde el punto de vista moral. 
Nada ganamos con sostener que todas las preferencias racionales e informadas tienen igual valor pero a algunas le damos especial preeminencia y a otras las relegamos porque así estaríamos mejor en términos utilitaristas; ya sea porque adoptamos como "regla" una determinada conducta que así lo exige o más contundentemente porque admitimos un determinado proceso decisorio no utilitarista. Debiéramos decir lisa y llanamente que el utilitarismo no nos da una explicación satisfactoria para estas cuestiones y por ello debemos abandonarlo en busca de una teoría moral más acorde a nuestras intuiciones.

De las dos versiones de utilitarismo desarrollada por Kymlicka sin dudas resulta más plausible la que se manifiesta como moral política. Su consecuencialismo y sus diferentes concepciones de utilidad ponen de manifiesto un fuerte compromiso con la humanidad desde el momento que se interesa por las consecuencias sociales de los actos y define el bien y mal no desde una posición metafísica, sino social.

En su génesis histórica el utilitarismo embistió contra teorías filosóficas y políticas que servían de fundamento a estructuras sociales que defendían los privilegios de unos pocos frente a las mayorías y que propiciaban la sumisión del hombre a mandatos divinos. En este sentido el utilitarismo fue claramente liberador.

El axioma que todas las personas importamos por igual, que todos somos merecedores de igual consideración y respeto, y de allí el compromiso de maximizar la utilidad parece una consecuencia loable pero puede dar lugar a consecuencias injustas.

Desde el punto de vista de la "estructura básica de la sociedad" el utilitarismo ataca la existencia de minorías privilegiadas, pero debe hacer uso de argumentos ad hoc para evitar legitimar abusos de las mayorías frente grupos minoritarios y marginales. La búsqueda de la maximización de la utilidad social implica que los intereses de los individuos no puedan prevalecer frente a la utilidad general; pero, por otro lado si no contamos con un criterio que nos permita sostener la existencia de determinados bienes sociales primarios sobre los cuales no puede prevalecer la utilidad social entonces abrimos la puerta a todo tipo de atropellos.

\section{El intuicionismo}

Otra vertiente contra la cual reacciona Rawls es el intuicionismo, que a diferencia del utilitarismo no constituye una teoría sistemática.

El intuicionismo afirma que existe una pluralidad de principios de justicia, a los cuales podemos acceder por medio de la intuición. Pero los mismos no se hallan jerárquicamente ordenados de modo que pueden entrar en conflicto entre sí; por otro lado tampoco nos esclarece mucho al no poder determinar criterios de admisibilidad de dichas intuiciones, de modo que no contamos con medios para discriminar intuiciones correctas de incorrectas, tampoco verdaderas intuiciones de meros pálpitos o impresiones (Gargarella. 2000, p. 22).

Es claro que el intuicionismo constituye un rival muy débil al momento de reconocer su propia incapacidad de crear un sistema de reglas capaz de jerarquizar nuestras intuiciones. Ello quiere decir que solo puede brindar soluciones ad hoc que pueden resultar contradictorias entre sí. 


\section{La teoría de la Justicia de Rawls}

No obstante estas disquisiciones y peligros que se hallan más allá de las buenas intenciones de los utilitaristas llevaron a John Rawls a lanzar críticas demoledoras contra el utilitarismo y elaborar una teoría de la Justicia alternativa de naturaleza constructivista.

Rawls (1997) sostiene que si la gente debiera elegir algún principio de moralidad política para regular la "estructura básica de la sociedad" a partir de una "situación original”, elegirían los principios que él postula.

Rawls imagina una situación previa a la constitución de la sociedad civil a través del contrato social. A esta situación la denomina "posición original"; se trataría de un estado natural pero no por ello igualitario, ya que las personas no tendrían similar poder de negociación -debido a sus desiguales aptitudes naturales, fuerza física, recursos iniciales, etc.

Este estado de naturaleza no permitiría a los individuos elegir un criterio de justicia imparcial; por el contrario seguramente plasmaría en el contrato social las ventajas naturales de unos pocos. Para evitar esta consecuencia no deseada, Rawls introduce un nuevo recurso argumental, el "velo de la ignorancia".

$\mathrm{Si}$ las personas se encontraran tras un velo de ignorancia, de modo que nadie supiese cual sería su lugar en la sociedad, su posición, su clase o status social, tampoco su sexo, inteligencia, fuerza física, etc., ni siquiera sus tendencias psicológicas especiales, se asegurarían las condiciones para un acuerdo justo, para la elección de un criterio de justicia imparcial.

Rawls se ocupa de determinar cuáles criterios de justicia distributiva adoptarían un conjunto de individuos racionales en un contexto de incertidumbre (a eso llama el velo de ignorancia) en el que desconocen todos los aspectos relevantes que hacen su identidad personal (posición social, sexo, raza, incluso inteligencia o carácter, etc.).

Según Rawls, los criterios van a ser justos si el procedimiento mediante el que se los adoptan es justo, con independencia de las distribuciones resultantes. Por eso su teoría es puramente procedimental.

Un proceso de decisión puramente procedimental se puede ejemplificar, como señala el propio Rawls, con una apuesta: si un grupo de personas acuerdan tirar los dados como medio para distribuir algo, lo más probable es que el resultado beneficie a unos y perjudique a otros, pero nadie podrá decir que el resultado es injusto si todos acordaron previamente el procedimiento de asignación.

Rawls se ocupa especialmente del procedimiento a utilizar para establecer los criterios de justicia. En este sentido considera que la gente acumula en la sociedad una serie de prejuicios e intereses privados (debidos, precisamente, a su posición social, clase social, raza, sexo, inteligencia, etc.) que hacen difícil la elección equitativa e imparcial de algún criterio de justicia. En ese contexto circunstanciado, cada quién elegiría de acuerdo a sus propios intereses, y no los sacrificaría en aras de la justicia. Entonces para lograr la elección imparcial de principios de justicia, Rawls crea el supuesto de que un conjunto de personas deberá elegir dichos principios, como si se hallaran tras un velo de ignorancia, en el que desconocen el tipo de sociedad en que vivirán, el 
lugar que ocuparán en ella, su clase social, su sexo, su inteligencia, su raza o cualesquiera otros rasgos personales o sociales que les permita identificarse con algún interés ajeno a la justicia.

Según Rawls, los individuos en esta situación, optarían según la regla del maximin; es decir, buscarán maximizar (mejorar) la situación de los más desfavorecidos, dado que nadie sabe cuál será su suerte en la sociedad, todo el mundo tratará de elegir aquel principio que le beneficie lo más posible si, al desaparecer el velo de ignorancia, se encuentra entre los más desfavorecidos de la sociedad (por ejemplo; si es pobre, o discapacitado o pertenece a una minoría discriminada, etc.).

Esto llevaría a los individuos a elegir un principio de justicia distributiva lo más igualitario posible, puesto que no tienen forma de saber que será cada quién cuando desaparezca el velo de ignorancia. Dado que desconocen su identidad social y personal, lo más racional sería que elijan el principio de justicia que les proporcione más bienes sociales primarios -aquellos que desea cualquier individuo racional para llevar adelante su plan de vida- si resulta que se hallan entre los más desfavorecidos de la sociedad.

Podemos apreciar que Rawls utiliza básicamente un argumento contractualista que, como tal, se hace merecedor de dos fuertes criticas. Por un lado como el estado de naturaleza pre-social y el mentado contrato social nunca han existido en la realidad, entonces ni los ciudadanos ni los gobiernos podrían estar obligados por él. Incluso si se postula que el contrato es un acuerdo hipotético que la gente hubiera firmado en un estado de naturaleza, entonces resultaría una falsedad, por cuanto no es un contrato en si mismo. Contundentemente sostiene Dworkin, un contrato hipotético; lisa y llanamente no es un contrato.

Expresa Kymlicka que la idea de un contrato social parece absurda (si es que se basa en acuerdos reales) o moralmente insignificante (si se basa en acuerdos hipotéticos).

No obstante, sostiene Dworkin, el argumento del contrato social puede ser interpretado, no como un primer acuerdo real o hipotético para encontrar los orígenes sociales de la sociedad, o las obligaciones históricas de los gobiernos o de los individuos, sino para conformar la idea de la igualdad moral de los individuos.

Pero de todas formas el argumento considerado en si mismo continua siendo una ficción y como tal dúctil a los intereses de su creador. El argumento del contrato social no resulta útil, no porque de él no podamos llegar a las conclusiones postuladas por Rawls o las de otros autores que hicieron uso de este recurso argumental, sino porque manipulándolas convenientemente podemos llegar a casi cualquier conclusión.

Se ha criticado incluso una variable que introduce Rawls en su teoría contractual -el "velo de la ignorancia"-, por ser psicológicamente irreal ya que resulta impensable un individuo desvinculado de su trasfondo social y sus deseos individuales, a lo que se respondió que el "velo de la ignorancia" no representa una teoría de la identidad personal, sino un recurso para asegurarse la equidad en la elección de los principios de justicia.

Finalmente, Kimlicka sostiene que la premisa de argumento de Rawls es la igualdad y no el contrato, y para criticarlo es necesario probar que no representa una concepción adecuada 
de la igualdad. No resultaría suficiente decir que el contrato es históricamente inadecuado, o que el velo de la ignorancia es psicológicamente irreal. La cuestión no es si la posición original existió alguna vez, sino si es probable que los principios que serían elegidos en ella resulten equitativos dada la naturaleza del proceso de selección.

A partir de Rawls el mundo de la filosofía moral (y política) cambió radicalmente. A partir de su teoría de la justicia nacieron o se revitalizaron importantes discusiones, y en tal sentido se acometieron distintos intentos por construir teorías alternativas de la justicia en contraste con la postulada por este autor, ya sea por considerarla insuficientemente igualitaria, o insuficientemente libertaria, o excesivamente individualista (Gargarella. 2000, p. 15-18).

Por razones de espacio resulta imposible exponer en este trabajo el amplio abanico de corrientes de pensamiento y teorías que se abrieron camino a partir de los trabajos de Rawls.

Finalmente, quedan por explicar las razones por las cuales solo se hace hincapié en la justicia, cuando la filosofía moral debe ocuparse también de otras virtudes; a eso solo podemos responder que no es una cuestión menor hacer centro en la Justicia y esto tiene una importante justificación porque para la tradición ética se trata de una bisagra entre la ética individual y la social (Cortina Orts. 1986, p. 130), y obviamente una filosofía moral orientada al Derecho debe estar más preocupada por la justicia social que por las actitudes de personas justas.

\section{CONCLUSIONES}

En el complejo y entramado mundo actual, quien sólo sabe de Derecho en realidad no sabe de Derecho. Esa afirmación que puede parecer un juego de palabras encierra un profundo significado; no es posible avocarse al análisis jurídico-formal con prescindencia de las razones que dan sustento a las soluciones jurídicas, las teorías que dan basamento a las instituciones y las consecuencias sociales y económicas de las intervenciones del Derecho.

El análisis económico y la filosofía moral nos brindan esas miradas alternativas de las que carecemos en la dogmática.

Consideramos importante construir un nuevo Derecho con una visión diferente e integradora, dado que en la complejidad del mundo actual la dogmática no puede ser concebida como una disciplina autosuficiente, con virtualidad explicativa necesaria para dar cuenta de todos los casos, especialmente los más complejos.

El interés analítico y la búsqueda de comprobaciones empíricas conducen a un entendimiento más realista, pragmático e instrumental de la realidad jurídica, y se constituye a la vez en un camino alternativo frente a las concepciones dogmáticas y esencialistas del Derecho.

Esta aproximación seguramente no resultará atractiva para quienes piensen que el sistema jurídico es algo diferente e independiente de las restantes ciencias sociales, y que consideren que el Derecho se encuentra reñido con los datos empíricos o que las normas se independizan de las justificaciones teóricas que les dan sustento. Pero no obstante ello, hemos pretendido circunvalar los falsos dilemas incoados por las concepciones más tradicionales, en 
la inteligencia que los juristas comprometidos sabrán comprender que resulta necesario abrir la dogmática a nuevas consideraciones que le aporten una mayor virtualidad explicativa al Derecho para así poder aprehender mejor las complejidades del mundo de hoy.

El Derecho debe incorporar mayores dosis de preocupación analítica y empírica en el estudio de temas jurídicos. Básicamente, remplazar descripciones y juicios de valor ocultos bajo el manto de descripciones ontológicas sobre la naturaleza jurídica de las instituciones, por explicaciones, análisis, contrastaciones de datos, y explicitación de presupuestos teóricos. En ese sentido la propuesta anglosajona constituye un interesante avance.-

\section{REFERENCIAS BIBLIOGRÁFICAS}

Alfaro Águila-Real, Jesús. (2007). "Los juristas -españoles- y el análisis económico del derecho", en InDret 1/2007.

Cortina Orts, Adela. (1986). "La justificación ética del Derecho como tarea prioritaria de la Filosofía Política. Una discusión desde John Rawls”, en Doxa 2.

Diaz, Rodolfo. (2006). “Alberdi: precursor del Análisis Económico del Derecho”; en Apuntes Jurídicos $\mathrm{N}^{\circ}$ 9, Mendoza.

Fischer, Stanley; DORNBUSH, Rudiger y SCHMELENSEE, Richard. ECONOMÍA. (1992). $2^{\circ}$ Ed. McGraw-Hill. Madrid.

Fiss, Owen. (1991). “¿La muerte del Derecho?”, en DOXA 10.

Fiss, Owen. (2001). LA AUTONOMÍA DEL DERECHO, en Estado de derecho y democracia, Un debate acerca del rule of law, SELA 2000, Buenos Aires, Argentina, p. 51-60. También en http://www.law.yale.edu/documents/pdf/Laautonomiadelderecho.pdf (Recuperado el 19 de febrero de 2012).

Gargarella, Roberto. LAS TEORÍAS DE LA JUSTICIA DESPUÉS DE RAWLS. Paidos. Buenos Aires, 2000.

González Amuchástegui, Jesús. (1994). "El Análisis Económico del Derecho: Algunas Cuestiones sobre su Justificación”, en DOXA 15-16.

Kymlicka, Will. (1995). FILOSOFÍA POLÍTICA CONTEMPORÁNEA: UNA INTRODUCCIÓN. Ariel. Barcelona. 
Lorenzatti, Ricardo Luis. (1999) “Análisis económico del Derecho: valoración, crítica. Hacia una teoría de la acción individual y colectiva en un contexto institucional”, en REVISTA DE DERECHO PRIVADO Y COMUNITARIO No 21. DERECHO Y ECONOMÍA. Editorial Rubinzal-Culzoni. Santa Fe.

Mercado Pacheco, Pedro. (1994). EL ANÁLISIS ECONÓMICO DEL DERECHO. Centro de Estudios Constitucionales. Madrid.

Pastor, Santos. (1989). SISTEMA JURÍDICO Y ECONOMÍA. UNA INTRODUCCIÓN AL ANÁLISIS ECONÓMICO DEL DERECHO. Tecnos. Madrid.

Polinsky, Mitchell. (1985). INTRODUCCIÓN AL ANÁLISIS ECONÓMICO DEL DERECHO. Ariel Derecho. Barcelona.

Rawls, John. (1997). TEORÍA DE LA JUSTICIA. Fondo de Cultura Económica. México.

Rojas, Ricardo; Schenone, Osvaldo; y Stordeur, Eduardo. (2012) NOCIONES DE ANÁLISIS ECONÓMICO DEL DERECHO PRIVADO. Mayaprin. Guatemala.

Cooter, Robert y Ulen, Thomas. (1998). DERECHO Y ECONOMÍA. FCE. México.

Cejudo Córdoba, Rafael. (2010). "Deontología y consecuencialismo: un enfoque informacional”, en CRÍTICA, Revista Hispanoamericana de Filosofía. Vol. 42, No. 126: 3-24.

Sagüés, María Sofía (2009). "El análisis económico del derecho en la jurisdicción constitucional: ponderación de la Unidad de Análisis Económico de Derecho de la Corte Suprema de Justicia de la Nación Argentina”, en LA LEY 2009-F, 1114.

Sastre Ariza, Santiago (2001). "Algunas consideraciones sobre la ciencia jurídica”, en DOXA 24.

Schäfer, Hans-Bernd y Ott, Claus. (1991). MANUAL DE ANÁLISIS ECONÓMICO DEL DERECHO CIVIL. Tecnos. Madrid.

Sola, Juan Vicente. (2008). "El análisis económico del derecho. O cómo tomarse las consecuencias seriamente”, en LA LEY 2008-B, 1350.

Sola, Juan Vicente. (2009). “La Corte Suprema y el análisis económico del derecho”, LA LEY 2009-E, 1223. 
Spector, Horacio (Comp). (2004) ELEMENTOS DE ANÁLISIS ECONÓMICO DEL DERECHO. Rubinzal-Culzoni. Santa Fe.

Spector, Horacio. (2003). "Justicia y Bienestar. Desde una perspectivas de Derecho Comparado", en Doxa 26.

Varian, Hal R. (1998). MICROECONOMÍA INTERMEDIA. Antoni Bosch. Barcelona.

\section{CURRICULUM VITAE}

CRISTIAN RICARDO ABEL PIRIS

Abogado. Magister en Derecho Privado. Doctor en Derecho.

Docente-Investigador Categoría III del Programa de Incentivos del Ministerio de Educación de la Nación.

Profesor Adjunto por Concurso de Instituciones del Derecho Privado I - Facultad de Ciencias Económicas (UNNE).

cpiris@unne.edu.ar 